\title{
PENGARUH STRUKTUR ORGANISASI DAN ANALISIS JABATAN TERHADAP MOTIVASI KERJA PEGAWAI (Studi pada SMK SMTI Kementerian Perindustrian di Indonesia)
}

\author{
Andhi Sukma Hanafi ${ }^{1}$, Saiful Bahri ${ }^{2}$ dan M. Shabri Abd. Majid ${ }^{3}$ \\ email: 4ndh15ukma@gmail.com, saiful.bahri511@gmail.com, mshabri@unsyiah.ac.id \\ ${ }^{1,2,3)}$ Universitas Syiah Kuala, Magister Manajemen, Fakultas Ekonomi dan Bisnis Jl. Tgk. Syech Abdul \\ Rauf, Kopelma Darussalam,Syiah Kuala, Kota Banda Aceh, 23111, Indonesia
}

\begin{abstract}
Abstrak
Penelitian ini dilatarbelakangi oleh pelaksanaan pembayaran tunjangan kinerja pegawai Sekolah Menengah Kejuruan-Sekolah menengah Teknologi Industri (SMK SMTI) Kementerian Perindustrian di Indonesia. Pembayaran tunjangan kinerja pegawai dipengaruhi oleh grade jabatan yang disusun oleh manajemen dituangkan dalam struktur organisasi dan analisa jabatan pada SMK SMTI Kementerian Perindustrian. Penelitian ini menggunakan metode deskriptif, adapun objek penelitian ini adalah struktur organisasi $\left(\mathrm{X}_{1}\right)$, analisis jabatan $\left(\mathrm{X}_{2}\right)$ dan Motivasi Kerja $(\mathrm{Y})$. Sedangkan subjek penelitian ini adalah SMK SMTI Kementerian Perindustrian di Indonesia. Berdasarkan hasil pengolahan data dan interprestasi data pada masing-masing variabel disimpulkan hasil penelitian: (1) Struktur organisasi pada SMK SMTI Kementerian Perindustrian sudah sangat baik, (2) Analisis jabatan pada SMK SMTI Kementerian Perindustrian sudah baik, (3) Motivasi kerja pada SMK SMTI Kementerian Perindustrian sudah sangat baik, (4) Terdapat pengaruh positif dengan tingkat signifikansi 0,609 antara variabel struktur organisasi terhadap variabel motivasi kerja, sehingga setiap ada perbaikan dalam struktur organisasi akan mengakibatkan peningkatan motivasi kerja, (5) Terdapat pengaruh positif dengan tingkat signifikansi 0,332 antara variabel analisis jabatan terhadap variabel motivasi kerja, sehingga setiap ada perbaikan dalam analisis jabatan akan mengakibatkan peningkatan motivasi kerja.
\end{abstract}

Kata kunci : Motivasi Kerja, Analisis Jabatan, Struktur Organisasi

\section{Pendahuluan}

Reformasi birokrasi merupakan salah satu upaya pemerintah untuk mencapai good governance dan melakukan pembaharuan dan perubahan mendasar terhadap sistem penyelenggaraan pemerintah terutama menyangkut aspek-aspek kelembagaan, ketatalaksanaan dan sumber daya manusia aparatur (Perpres Nomor 81/2010) ${ }^{[1]}$. Tujuan reformasi birokrasi adalah untuk menciptakan birokrasi pemerintah yang profesional dengan karakteristik, berintegrasi, berkinerja tinggi, bebas dan bersih KKN, mampu melayani publik, netral, sejahtera, berdedikasi dan memegang teguh nilai-nilai dasar dan kode etik aparatur negara. Upaya Kementerian Perindustrian dalam melaksanakan reformasi birokrasi adalah membentuk tim kerja reformasi birokrasi Kementerian Perindustrian (Kepmenperin Nomor 250/M-IND/Kep/3/ 2016) ${ }^{[2]}$.
Tim reformasi birokrasi Kementerian Perindustrian bertugas untuk menciptakan birokrasi pemerintah yang profesional dilingkungan Kementerian Perindustrian sesuai dengan tujuan reformasi birokrasi yang telah ditetapkan. Reformasi birokrasi yang dilakukan pada Kementerian Perindustrian meliputi sembilan area perubahan (manajemen perubahan, penguatan pengawasan, penguatan akuntabilitas kinerja, penataan organisasi, penataan tata laksana, penataan sistem manajemen sumber daya manusia (SDM) aparatur, penataan peraturan perundangundangan, peningkatan kualitas pelayanan publik, dan quick wins.

Sekolah Menengah Kejuruan-Sekolah Menengah Teknologi Industri (SMK SMTI) sebagai unit pelaksana pendidikan dilingkungan Kementerian Perindustrian juga berkewajiban untuk melaksanakan program reformasi birokrasi dilingkungan Kementerian Perindustrian. Dalam penataan 
organisasi yang dilakukan oleh tim reformasi birokrasi sangat erat hubungannya dalam penetapan struktur organisasi SMK SMTI di Indonesia. Sedangkan dalam penataan sistem sumber daya manusia aparatur mencakup ruang lingkup analisis jabatan masing-masing pegawai SMK SMTI di Indonesia. Dalam penataan sistem manajemen SDM aparatur SMK SMTI berpedoman pada Permenperin Nomor 98/M-IND/Per/11/2015 $5^{[3]}$.

Sebagai kelanjutan dalam pelaksanaan Permenperin Nomor 98/MIND/Per/11/2015, pegawai SMK SMTI di Indonesia memperoleh tunjangan atas kinerjanya yang diukur berdasarkan sasaran kerja pegawai dan produktifitas kerjanya. Namun yang paling mendasar adalah penentuan grade jabatan oleh pihak manajemen, yang sangat dipengaruhi oleh struktur organisasi dan analisis jabatan yang sudah dilakukan. Dalam penelitian ini akan dibahas lebih lanjut mengenai bagaimana tingkat motivasi kerja pegawai yang dipengaruhi oleh struktur organisasi dan analisis jabatan pada SMK SMTI di Indonesia.

Motivasi kerja adalah suatu kondisi yang menyebabkan pegawai melakukan pekerjaan untuk mencapai kebutuhan yang memberi kepuasan kepada pegawai dan berpengaruh terhadap pencapaian tujuan organisasi. (Bangun, 2012) ${ }^{[4]}$. Motivasi kerja yang dimaksud adalah bagaimana pegawai SMK SMTI di Indonesia dalam melakukan pekerjaan untuk mencapai kebutuhan dalam hal ini tunjangan kinerja dan pengaruhnya terhadap pencapaian tujuan organisasi.

Menurut Rizka (2015) $)^{[5]}$, bahwa yang menjadi indikator motivasi kerja seseorang terdiri atas: mutu pekerjaan meningkat, tugas sesuai kemampuan, inisiatif kerja tinggi, hubungan kerja antara pimpinan dan pegawai, pengorbanan yang diberikan pegawai. Berdasarkan penjelasan diatas, maka indikator motivasi kerja, dijelaskan:

a. Mutu pekerjaan, merupakan peningkatan hasil pekerjaan baik secara kuantitas dan kualitas.

b. Pelaksanaan tugas, merupakan kemampuan yang harus dimiliki untuk melaksanakan tugas/pekerjaan. c. Inisiatif, merupakan keinginan/prakarsa dari pegawai untuk melaksanakan pekerjaan.

d. Hubungan kerja, merupakan hubungan kerja antara pimpinan dan pegawai.

e. Pengorbanan, merupakan pengakuan dan penghargaan yang diberikan kepada pegawai yang telah melaksanakan pekerjaan.

Struktur organisasi dapat diartikan sebagai kerangka kerja formal organisasi yang dengan kerangka kerja itu tugas-tugas pekerjaan dibagi-bagi, dikelompokkan dan dikoordinasikan (Robbins, 2008) ${ }^{[6]}$. Struktur organisasi yang dimaksud adalah struktur organisasi SMK SMTI yang berpengaruh terhadap penentuan grade pegawai. Menurut Kates dan Galbraith $(2007)^{[7]}$, Struktur organisasi adalah proses meninjau dan mengkonfigurasi struktur, proses, sistem penghargaan, dan aktivitas orang atau individu untuk menciptakan suatu organisasi yang efektif yang mampu mencapai strategi bisnis. Menurut Wahjono $(2010)^{[8]}$ ada empat bagian sebagai elemen ataupun unsur untuk membangun struktur organisasi, yaitu pembagian kerja, departemenalisasi, hirarki dan koordinasi.

Menurut Ardana (2008) ${ }^{[9]}$ ada dua faktor yang mempengaruhi motivasi yaitu motivasi intrinsik dan motivasi ekstrinsik. Motivasi intrinsik merupakan motivasi yang berasal dari rangsangan di dalam perusahaan. Pada umumnya karakteristik individu turut mempengaruhi bagaimana orang menilai apa yang diperolehnya dari rangsangan dalam perusahaan. Motivasi ekstrinsik diwujudkan dalam bentuk rangsangan dari luar yang bertujuan menggerakkan individu untuk melakukan suatu aktifitas yang membawa manfaat kepada individu itu sendiri. Motivasi ekstrinsik ini dapat dirangsang dalam bentuk-bentuk seperti gaji, lingkungan kerja, hubungan antar manusia, kebijakan atau peraturan perusahaan, pimpinan atau supervisi.

Tujuan lebih nyata adanya desain struktur organisasi yakni dapat mempengaruhi motivasi dan komitmen anggota untuk mencapai tujuan organisasi (Philip, 2000) ${ }^{[10]}$. Desain organisasi memunyai implikasi-implikasi penting pada 
manfaat kompetitif perusahaan dimana salah satunya untuk meningkatkan koordinasi dan motivasi para pekerja (Wisnu, 2005) ${ }^{[11]}$.

Indikator struktur organisasi menurut Robbins $(2008)^{[6]}$, adalah spesialisasi pekerjaan, departementalisasi, rantai komando, rentang kendali, sentralisasi dan desentralisasi, dan formalisasi. Adapun indikator yang akan digunakan dalam penelitian ini adalah sebagai berikut:

a. Spesialisasi pekerjaan, adalah sejauh mana tugas-tugas dalam organisasi dibagi-bagi ke dalam beberapa pekerjaan tersendiri.

b. Departementalisasi, dasar yang dipakai untuk mengelompokkan pekerjaan secara bersama-sama. Departementalisasi dapat berupa proses, produk, geografi, dan pelanggan.

c. Rantai komando, garis wewenang yang tanpa putus yang membentang dari puncak organisasi ke eselon paling bawah dan menjelaskan siapa bertanggung jawab kepada siapa.

d. Rentang kendali, jumlah bawahan yang dapat diarahkan oleh seorang Koordinator Kegiatan secara efisien dan efektif.

e. Formalisasi, sejauh mana pekerjaanpekerjaan di dalam organisasi dibakukan dalam bentuk Standar Operasional Kerja (SOP).

Analisis jabatan adalah suatu bentuk pengembangan uraian terperinci dari tugastugas yang harus dilakukan dalam suatu jabatan, penentuan hubungan dari suatu jabatan dengan jabatan lain yang ada, dan penentuan tentang pengetahuan, keterampilan dan kemampuan-kemampuan lain yang diperlukan pegawai untuk melakukan pekerjaan secara efektif dan efisien (Robbins, 2008) ${ }^{[6]}$. Analisis jabatan disini merupakan analisis jabatan pegawai SMK SMTI di Indonesia untuk melaksanakan pekerjaan secara efektif dan efisien.

Analisis jabatan merupakan hal yang perlu dilakukan oleh organisasi sebagai dasar dalam penentuan strategi sumber daya manusia yang tepat dalam menghadapi perkembangan organisasi yang semakin dinamis (Robbins, 2008) ${ }^{[6]}$. Definisi analisis jabatan (job analysis) merupakan suatu proses yang sistematik untuk mengetahui mengenai isi dari suatu jabatan (job content) yang meliputi tugas-tugas, pekerjaanpekerjaan, tanggung jawab, kewenangan, dan kondisi kerja, dan mengenai syaratsyarat kualifikasi yang dibutuhkan (job requirements) seperti pendidikan, keahlian, kemampuan, pengalaman kerja dan lainlain, agar seseorang dapat menjalankan tugas-tugas dalam suatu jabatan dengan baik (Sofyandi, 2008) $)^{[12]}$.

Adapun indikator yang digunakan dalam penelitian ini adalah sebagai berikut:

a. Wewenang, merupakan hak dan kekuasaan untuk mengajukan pendapat dan mengambil keputusan atau tindakan yang diperlukan dalam melaksanakan pekerjaan yang melekat dalam suatu jabatan. Kewenangan harus terdefinisikan dengan jelas, tidak overlapping dengan jabatan lain, dan sesuai dengan jabatan pegawai.

b. Tanggung jawab, merupakan kesadaran pegawai akan tingkah laku atau perbuatan baik dalam melaksanakan pekerjaan, sebagai perwujudan kesadaran akan kewajiban.

c. Kondisi kerja, merupakan serangkaian kondisi atau keadaan lingkungan kerja pada instansi yang menjadi tempat bekerja dari para pegawai yang bekerja. Yang dimaksud kondisi kerja yang baik yaitu kondisi yang nyaman dan mendukung pegawai untuk melaksanakan pekerjaan. Adapun yang mendukung pelaksanaan pekerjaan pegawai dapat berupa peraturan/kebijaksanaan dan koordinasi dalam melaksanakan pekerjaan.

d. Fasilitas kerja, merupakan segala sesuatu yang terdapat dalam instansi yang bisa dinikmati oleh pegawai, sebagai kebutuhan pelaksanaan pekerjaan dan mendukung kelancaran pelaksanaan pekerjaan.

e. Standar hasil kerja, merupakan target, sasaran, atau tujuan kerja pegawai dalam ukuran waktu tertentu. Standar hasil kerja dalam pelaksanaannya harus disesuaikan dengan target yang akan 
dicapai dalam suatu pekerjaan dan dapat diukur dengan waktu tertentu.

f. Pendidikan, merupakan pendidikan formal, yaitu kegiatan yang sistematis, bertingkat/berjenjang, dimulai dari sekolah dasar sampai dengan perguruan tinggi dan yang setaraf dengannya. Tingkat/jenjang pendidikan pegawai harus disesuaikan dengan pelaksanaan pekerjaan.

g. Pelatihan, merupakan proses melatih pegawai agar dapat meningkatkan kemampuan pegawai dalam menunjang pelaksanaan pekerjaan.

h. Kompetensi, merupakan kemampuan pegawai yang berupa pengetahuan, keahlian, ketrampilan, dan minat untuk menunjang pekerjaan secara efektif.

Dari uraian masalah diatas, maka tujuan dari penelitian ini adalah:

$\mathrm{H}_{1}$ Mendeskripsikan struktur organisasi pada SMK SMTI di Indonesia.

$\mathrm{H}_{2}$ Mendeskripsikan analisis jabatan pada SMK SMTI di Indonesia.

$\mathrm{H}_{3}$ Mendeskripsikan motivasi kerja pegawai SMK SMTI di Indonesia.

$\mathrm{H}_{4}$ Menguji pengaruh dan tingkat signifikan antara struktur organisasi terhadap motivasi kerja pegawai SMK SMTI di Indonesia.

$\mathrm{H}_{5}$ Menguji pengaruh dan tingkat signifikan antara analisis jabatan terhadap motivasi kerja pegawai SMK SMTI di Indonesia.

\section{Metode Penelitian}

Penelitian ini menggunakan metode deskriptif, dengan tujuan utama agar dapat memberikan gambaran atau deskripsi keadaan struktur organisasi, analisis jabatan, dan motivasi kerja pada SMK SMTI di Indonesia secara obyektif.

Untuk menganalisis data digunakan Structural Equation Modeling (SEM) menggunakan software AMOS 20 dalam model dan pengujian hipotesis. Model penelitian menggunakan AMOS seperti terlihat pada Gambar 1.

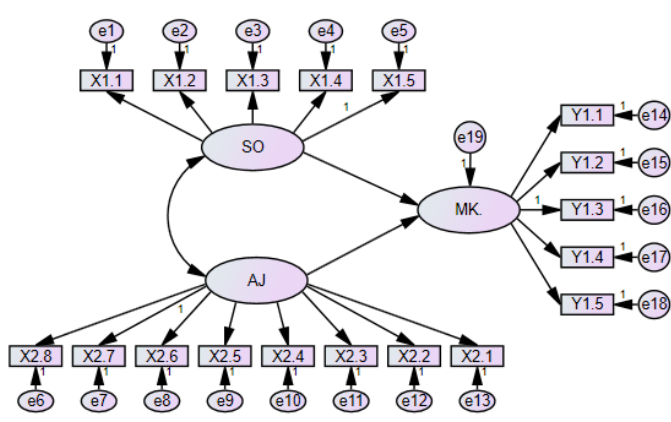

Gambar 1. Model Penelitians

Keterangan:

$\mathrm{SO}=$ Struktur Organisasi

$\mathrm{AJ}=$ Analisis Jabatan

MK $=$ Motivasi Kerja

Populasi menurut Sujarweni $(2012)^{[13]}$ didefinisikan sebagai wilayah generalisasi yang terdiri atas objek atau subjek yang mempunyai kualitas dan karakteristik tertentuyang ditetapkan oleh peneliti untuk dipelajari kemudian ditarik kesimpulannya. Populasi dari penelitian ini adalah seluruh pegawai pada SMK SMTI di Indonesia berjumlah 339 pegawai.

Teknik pengambilan sampel dalam penelitian ini menggunakan multistage sampling. Metode ini merupakan bentuk kompleks dari metode cluster sampling. Multistage sampling dilakukan karena sumber data tersebar pada enam propinsi di seluruh Indonesia. Sedangkan sampel ditentukan dengan menggunakan rumus slovin (Sanusi, 2011) ${ }^{[14]}$ sehingga diperoleh jumlah sampel sebanyak 183 pegawai.

Uji validitas dengan uji convergent validitas, yaitu menguji konstruk (indikator) apakah memiliki proporsi variance yang tinggi atau tidak. Adapun kriteria yang harus dipenuhi adalah loading factor atau standardized loading estimate >0,500. Loading factor yang digunakan untuk mengukur kontribusi masing-masing indikator bila nilainya diatas 0,500 maka dikatakan indikator itu cukup representative untuk menerangkan unobserved variabelnya.

Uji Reliabilitas adalah ukuran mengenai konsistensi internal dari indikator-indikator sebuah konstruk yang menunjukkan derajat sampai dimana masing-masing indikator itu mengindikasikan sebuah konstruk/ faktor laten yang umum. Dengan kata lain 
bagaimana hal-hal yang spesifik saling membantu dalam menjelaskan sebuah fenomena yang umum. Construct Reliability diperoleh melalui rumus berikut (Ferdinand, 2006) $)^{[15]}$.

Uji normalitas data dengan normalitas univariate dan multivariate, yaitu menganalisis tingkat normalitas data yang digunakan dalam penelitian ini. Univariate melihat nilai CR pada Skewness diharapkan disekitar \pm 2.58 . Bila ada nilai diluar angka tersebut bisa ditoleransi apabila nilai Multivariatenya masih disekitar \pm 2.58

Uji fit model, dilakukan untuk menguji apakah sebuah model dapat diterima atau ditolak (Ferdinand, 2006) ${ }^{[15]}$, dengan beberapa indeks kesesuaian dan cut-off value.

- $C 2-C h i-S q u a r e$ statistic, semakin kecil nilai $\mathrm{C} 2$ semakin baik model itu, dan diterima berdasarkan probabilitas dengan cut-off value sebesar $\mathrm{p}>0,05$ atau $\mathrm{p}>0,010$.

- RMSEA (The Root Mean Square Error of Approximation), merupakan ukuran yang mencoba memperbaiki kecenderungan statistic chi-square menolak model dengan jumlah sampel yang besar. Nilai RMSEA antara 0,05 sampai 0,08 merupakan ukuran yang dapat diterima. Model cocok untuk menguji model konfirmantori atau competing model strategy dengan jumlah besar.

- GFI (Goodness of Fit Index), adalah ukuran non statistical yang mempunyai rentang nilai antara 0 (poor fit) sampai dengan 1,0 (perfect fit). Nilai yang tinggi dalam indeks ini menunjukkan sebuah "goodfit" adalah $>0,90$.

- AGFI (Adjusted Goodness of Fit Index), dimana tingkat penerimaan yang direkomendasikan adalah bila AGFI mempunyai nilai sama dengan atau lebih besar dari 0,90.

- CMIN/DF, adalah The Minimum Sample Discrepancy Function yang dibagi dengan degree of freedom. CMIN/DF tidak lain adalah statistik chi-square $(x 2)$ relatif. Bila nilai $x 2$ relatif kurang dari 2,0 atau 3,0 adalah indikasi dari acceptable fit antara model dan data.
- TLI (Tucker Lewis Index), merupakan incremental index yang membandingkan sebuah model yang diuji terhadap sebuah baseline model, dimana nilai yang direkomendasikan sebagai acuan untuk diterimanya sebuah model adalah $>0,90$.

- CFI (Comparative Fit Index), dimana bila mendekati 1 , mengindikasi tingkat fit yang paling tinggi. Nilai yang direkomendasikan adalah CFI lebih besar atau sama dengan 0,90 .

Alat ukur dalam penelitian ini menggunakan Skala Likert dengan memberikan nilai skor terhadap alternatif jawaban yang telah disediakan pada masingmasing pertanyaan dalam kuisioner yang berkaitan dengan variabel eksogen yaitu struktur organisasi dan analisis jabatan, sedangkan variabel endogen yaitu motivasi kerja. Nilai Skala Likert tersebut adalah seperti terlihat pada Tabel 1.

Tabel 1. Skala Likert

\begin{tabular}{|l|c|}
\hline \multicolumn{1}{|c|}{ Alternatif } & Skala \\
\hline Sangat Setuju (SS) & 5 \\
\hline Setuju (S) & 4 \\
\hline Kurang Setuju (KS) & 3 \\
\hline Tidak Setuju (TS) & 2 \\
\hline Sangat Tidak Setuju (STS) & 1 \\
\hline
\end{tabular}

Uji hipotesis deskriptif dilaksanakan dengan melihat nilai mean dari data hasil penelitian. Melalui angka mean tersebut akan diketahui sejauh mana derajat persepsi responden atas variabel-variabel yang menjadi indikator dalam penelitian ini. Untuk menjelaskan masing-masing variabel tersebut, akan digunakan tabel kategorikal seperti yang tertera pada Tabel 2 .

Tabel 2. Rentang Kategorikal Deskriptif

\begin{tabular}{|c|c|}
\hline Rentang Nilai & Kategori \\
\hline $4,20-5,00$ & Sangat Baik \\
\hline $3,40-4,19$ & Baik \\
\hline $2,60-3,39$ & Netral \\
\hline $1,80-2,59$ & Tidak Baik \\
\hline $1,00-1,79$ & Sangat Tidak Baik \\
\hline
\end{tabular}

Tabel kategorikal diatas menggunakan rentang atau interval 0,8 yang didapat dari pengurangan nilai terbesar pada Skala Likert 5 dan nilai terkecil 1 dibagi dengan jumlah kategorisasi itu sendiri 5, (Sujarweni, 2012) ${ }^{[13]}$.

Sedangkan untuk menguji pengaruh antara variabel eksogen yaitu struktur 
organisasi dan analisis jabatan terhadap variabel endogen yaitu motivasi kerja, peneliti menggunakan AMOS. Uji hipotesis verifikatif dilaksanakan dengan melihat nilai Critical Ratio (CR) dan Probability (P). Apabila nilai $C R>1,96$ dan nilai $P<0,05$, maka dapat dikatakan terdapat pengaruh antar variabel yang diuji. Sedangkan nilai pengaruh dapat dilihat dari nilai estimate. Jika nilai $\mathrm{CR}<1,96$ dan nilai $\mathrm{P}>0,05$, maka $\mathrm{H}_{0}$ diterima dan $\mathrm{H}_{\mathrm{a}}$ ditolak. Jika nilai $\mathrm{CR}>1,96$ dan nilai $\mathrm{P}<0,05$, maka $\mathrm{H}_{0}$ ditolak dan $\mathrm{H}_{\mathrm{a}}$ diterima.

\section{Hasil dan Pembahasan}

$\mathrm{H}_{1}$ Struktur organisasi pada SMK SMTI di Indonesia.

Struktur organisasi pada SMK SMTI di Indonesia dipersepsikan secara positif oleh responden. Hal ini dapat dilihat dari indikator spesialisasi pekerjaan, departementalisasi, rantai komando, rentang kendali, dan formalisasi yang memiliki ratarata antara 4,20-5,00 (sangat baik). Adapun rata-rata dari seluruh indikator struktur organisasi mencapai nilai 4,38 sehingga struktur organisasi pada SMK SMTI di Indonesia dinilai sudah sangat baik.

\section{$\mathrm{H}_{2}$ Analisis jabatan pada SMK SMTI di Indonesia.}

Analisis jabatan pada SMK SMTI di Indonesia dipersepsikan secara positif oleh responden. Hal ini dapat dilihat dari indikator tanggung jawab, standar hasil kerja, dan kompetensi yang memiliki ratarata antara 4,20-5,00 (sangat baik). Sedangkan untuk indikator wewenang, kondisi kerja, fasilitas kerja, pendidikan, dan pelatihan memiliki rata-rata antara 3,404,19 (baik). Adapun rata-rata dari seluruh indikator analisis jabatan mencapai nilai 4,14 sehingga analisis jabatan pada SMK SMTI di Indonesia dinilai sudah baik.

\section{$\mathrm{H}_{3}$ Motivasi kerja pegawai SMK SMTI di Indonesia.}

Motivasi kerja pada SMK SMTI di Indonesia dipersepsikan secara positif oleh responden. Hal ini dapat dilihat dari indikator mutu pekerjaan, pelaksanaan tugas, inisiatif, dan hubungan kerja yang memiliki rata-rata antara 4,20-5,00 (sangat baik). Sedangkan untuk indikator pengorbanan memiliki rata-rata antara 3,404,19 (baik). Adapun rata-rata dari seluruh indikator motivasi kerja mencapai nilai 4,43 sehingga motivasi kerja pada SMK SMTI di Indonesia dinilai sudah sangat baik (tinggi).

\section{$\mathrm{H}_{4}$ Pengaruh dan tingkat signifikan antara struktur organisasi terhadap motivasi kerja pegawai SMK SMTI di Indonesia.}

Pengaruh dan tingkat signifikansi antara struktur organisasi terhadap motivasi kerja dapat dilihat pada Tabel 3 .

Tabel 3. Hasil analisa menggunakan AMOS

\begin{tabular}{|c|c|c|c|}
\hline Uraian & C.R & $\mathbf{P}$ & Beta \\
\hline $\mathrm{SO} \rightarrow \mathrm{MK}$ & 4,331 & $* * *$ & 0609 \\
\hline
\end{tabular}

Nilai C.R. $=4,331>1,96$ dan nilai $\mathrm{P}=$ $* * *<0,05$ sehingga $\mathrm{H}_{\mathrm{a}}$ Diterima. Terdapat pengaruh antara variabel independen struktur organisasi terhadap variabel dependen motivasi kerja, adapun tingkat signifikan hubungan antara struktur organisasi terhadap motivasi kerja senilai 0,609 (setiap ada perbaikan dalam struktur organisasi akan mengakibatkan peningkatan motivasi kerja). Dengan demikian untuk $\mathrm{H}_{4}$ yang menyatakan struktur organisasi berpengaruh secara signifikan terhadap motivasi kerja pegawai SMK SMTI di Indonesia dapat diterima. Hasil penelitian ini konsisten dengan penelitian yang dilakukan Rizka (2015) $)^{[5]}$, dimana hasil penelitian menunjukkan bahwa struktur organisasi berpengaruh signifikan terhadap motivasi kerja

\section{$\mathrm{H}_{5}$ Pengaruh dan tingkat signifikan antara analisis jabatan terhadap motivasi kerja pegawai SMK SMTI di Indonesia.}

Pengaruh dan tingkat signifikansi antara analisis jabatan terhadap motivasi kerja dapat dilihat pada Tabel 4.

Tabel 4. Hasil analisa menggunakan AMOS

\begin{tabular}{|c|c|c|c|}
\hline Uraian & C.R & P & Beta \\
\hline $\mathrm{AJ} \rightarrow \mathrm{MK}$ & 3,783 & $* * *$ & 0,332 \\
\hline
\end{tabular}

$* * *$ Tingkat signifikansi $<0,001$ 
Nilai C.R. $=3,783>1,96$ dan nilai $\mathrm{P}=$ *** $<0,05$ sehingga Ha Diterima. Terdapat pengaruh antara variabel independent analisis jabatan terhadap variabel dependen motivasi kerja, adapun tingkat signifikan hubungan antara analisis jabatan terhadap motivasi kerja senilai 0,332 (setiap ada perbaikan dalam analisis jabatan akan mengakibatkan peningkatan motivasi kerja). Dengan demikian untuk $\mathrm{H}_{5}$ yang menyatakan analisis jabatan berpengaruh secara signifikan terhadap motivasi kerja pegawai SMK SMTI di Indonesia dapat diterima. Hasil penelitian ini konsisten dengan penelitian yang dilakukan Wulandari (2011) dan Rizka (2015)[5], dimana hasil penelitian menunjukkan bahwa analisis jabatan berpengaruh signifikan terhadap motivasi kerja

\section{Kesimpulan}

Struktur organisasi, Analisis jabatan, Motivasi kerja pada SMK SMTI di Indonesia dipersepsikan secara positif oleh responden. Hal ini dapat dilihat dari indikator yang memiliki rata-rata yang baik. Pengaruh dan tingkat signifikansi antara struktur organisasi terhadap motivasi kerja memperoleh hasil yang menunjukkan bahwa struktur organisasi berpengaruh signifikan terhadap motivasi kerja. Pengaruh dan tingkat signifikansi antara analisis jabatan terhadap motivasi kerja memperoleh hasil yang menunjukkan bahwa analisis jabatan berpengaruh signifikan terhadap motivasi kerja.

\section{Daftar Pustaka}

[1] Peraturan Presiden Nomor 81 tahun 2010 tentang Grand Design Reformasi Birokrasi 2010-2025.

[2] Keputusan Menteri perindustrian nomor 250/M-IND/Kep/3/2016 tentang Pem-bentukan Tim Reformasi Birokrasi Kementerian Perindustrian.

[3] Peraturan Menteri Perindustrian Nomor 98/M-IND/PER/11/2015 tentang Meka-nisme Pemberian Tunjangan Kinerja Bagi Pegawai di Lingkungan Kementerian Perindustrian
[4] Bangun, W. (2012). Manajemen Sumber Daya Manusia. Jakarta : Gelora Penerbit Erlangga.

[5] Rizka, N. Yusuf, R. Majid, M.S.A. (2015). Pengaruh struktur organisasi dan analisis jabatan terhadap motivasi kerja dan dampaknya pada kinerja sekretariat Majelis Permusyawaran Ulama (MPU) Aceh. Jurnal Manajemen Pascasarjana Universitas Syiah Kuala, ISSN 2302-0199, pp 1-9.

[6] Robbins, S., dan Timothy A. J. (2008). Perilaku Organisasi, Organizational Behaviour. Buku Terjemahan. Jakarta: Gramedia.

[7] Kates, A. and Galbraith, J.R. (2007). Designing your organization: Using the star model to solve 5 critical design challenge. First edition. USA: JosseyBass Publisher.

[8] Wahjono, S , I. (2010). Perilaku Organisasi. Yogyakarta: Graha Ilmu.

[9] Ardana, Komang. Dkk. (2008). Perilaku Keorganisasian. Yogyakarta: Graha Ilmu.

[10] Philip, S. (2000). Mendesain Organisasi. Jakarta: Pustaka Binaman Pressindo.

[11] Wisnu, D., Nurhasanah, S. (2005). Teori Organisasi, Struktur dan Desain. Malang: UMM Press.

[12] Sofyandi, H. (2008). Manajemen Sum-ber Daya Manusia. Edisi Pertama. Yogyakarta: Graha Ilmu.

[13] Sujarweni, V.W dan Endrayanto, P. (2012). Statistika Untuk Penelitian. Yogyakarta: Graha Ilmu.

[14] Sanusi, A. (2011). Metode Penelitian Bisnis. Jakarta: Salemba Empat.

[15] Ferdinand, A. (2006). Structural Equation Modeling dalam Penelitian Manajemen. Semarang: Universitas Diponegoro. 